\title{
Metformin induces an intracellular reductive state that protects oesophageal squamous cell carcinoma cells against cisplatin but not copper-bis(thiosemicarbazones)
}

\author{
Leonard Howard Damelin ${ }^{1,2+}$, Rupal Jivan ${ }^{3 \dagger}$, Robin Bruce Veale ${ }^{3}$, Amanda Louise Rousseau ${ }^{4}$
} and Demetra Mavri-Damelin ${ }^{3^{*}}$

\begin{abstract}
Background: Oesophageal squamous cell carcinoma (OSCC) is a highly aggressive carcinoma with a poor survival rate. One of the most commonly used chemotherapeutic drugs, cisplatin, displays varied and often poor efficacy in vivo. Therefore, alternative, cost-effective and more efficacious treatments are required. Metformin has been previously shown to reduce proliferative rates in various carcinoma cell lines. We report for the first time, the effect of metformin on OSCC cell proliferation and show that it antagonises cisplatin-induced but not copper-bis (thiosemicarbazone)-induced cytotoxicity in OSCC cells.
\end{abstract}

Methods: Cell proliferation and stage of the cell cycle were quantified by trypan blue counts and flow cytometry, respectively. All cytotoxicity measurements were made using the tetrazolium based MTT assay. Metabolic alterations to cells were determined as follows: glycolysis via a lactate dehydrogenase assay, reducing equivalents by MTT reduction and reduced intracellular thiols by monobromobimane-thiol fluorescence, and glutathione depletion using buthionine sulfoximine. Inductively coupled plasma mass spectrometry was used to quantify cisplatin-DNA adduct formation.

Results: Metformin was found to reduce cell proliferation significantly in all OSCC cell lines, with an accumulation of cells in G0/G1 phase of the cell cycle. However, metformin significantly protected OSCC cells against cisplatin toxicity. Our results indicate that a major mechanism of metformin-induced cisplatin resistance results from a significant increase in glycolysis, intracellular $\mathrm{NAD}(\mathrm{P}) \mathrm{H}$ levels with a concomitant increase in reduced intracellular thiols, leading to decreased cisplatin-DNA adduct formation. The glutathione synthesis inhibitor buthionine sulfoximine significantly ablated the protective effect of metformin. We subsequently show that the copper-bis (thiosemicarbazones), Cu-ATSM and Cu-GTSM, which are trapped in cells under reducing conditions, cause significant OSCC cytotoxicity, both alone and in combination with metformin.

(Continued on next page)

\footnotetext{
* Correspondence: Demetra.Mavri-Damelin@wits.ac.za

${ }^{\dagger}$ Equal contributors

${ }^{3}$ School of Molecular and Cell Biology, University of the Witwatersrand,

Private Bag X3, Johannesburg 2050, South Africa

Full list of author information is available at the end of the article
} 
(Continued from previous page)

Conclusions: This is the first study showing that metformin can be used to decrease cell proliferation in OSCC cells. However, metformin protects against cisplatin cytotoxicity by inducing a reducing intracellular environment leading to lower cisplatin-DNA adduct formation. As such, we advise that caution be used when administering cisplatin to diabetic patients treated with metformin. Furthermore, we propose a novel combination therapy approach for OSCC that utilises metformin with metformin-compatible cytotoxic agents, such as the copper-bis (thiosemicarbazones), Cu-ATSM and Cu-GTSM.

Keywords: Oesophageal squamous cell carcinoma, Metformin, Copper bis(thiosemicarbazones), Metabolism, Cisplatin, Thiol, Glutathione

\section{Background}

Oesophageal carcinoma, of which there are two subtypes, adenocarcinoma and squamous cell carcinoma, is the sixth most common cause of cancer-related death [1]. Oesophageal squamous cell carcinoma (OSCC) is a highly aggressive carcinoma with a very poor survival rate that occurs with particularly high frequency in developing countries including Iran, China, South Africa, and Brazil, where mortality rates can exceed 100 per 100,000 population. In developed countries, incidence rarely exceeds 10 per 100,000 population [2,3], with the exceptions of certain regions in North-West France and Northern Italy where incidence may reach 30 and 2 per 100,000 in males and females, respectively [4]. The causes of OSCC are multiple and varied, probably reflecting repeated exposure to dietary components, such as $\mathrm{N}$-nitroso compounds, excessive smoking and alcohol consumption, chronic inflammation and possibly, genetic predisposition [5]. Current commonly used therapies for OSCC include 5 -fluorouracil and cisplatin, which show poor efficacy and often display both chemotoxicity and chemoresistance [6]. Cisplatin has multiple mechanisms of cytotoxicity including the formation of DNA and protein adducts, as well as via oxidative stress. Many resistance mechanisms for cisplatin have been identified, including, pertinent to this study, sequestering of cisplatin by glutathione (a major species of intracellular thiols). This results in export of cisplatin-glutathione adducts leading to a reduction in cisplatin-mediated DNA damage [7-9]. Investigations into more effective targeted treatment options for OSCC using monoclonal antibody therapies are very promising [10] however, access to such therapies in developing countries is extremely limited, primarily due to cost. Therefore, there is a continued and urgent requirement for alternative, effective and economical treatment options.

Recently, the well characterized and tolerated antidiabetic drug, metformin has been the subject of intense investigations in cancer research. Population studies have shown that this biguanide, conventionally used to decrease peripheral glucose levels and increase insulin sensitivity in diabetic and pre-diabetic patients [11,12], reduced breast cancer occurrence in female patients with type 2 diabetes [13]. Since then, metformin has been observed to reduce the proliferation of many types of carcinoma cell lines and diabetic patients taking metformin have been found to have better recovery rates from breast cancer [14-17]. Furthermore, metformin has been shown to target cancer stem cells [18]. However, whilst metformin reduces cell proliferation in most cancer types, it rarely causes apoptosis, and is therefore being combined with conventional chemotherapeutic drugs, including cisplatin. This treatment combination has mixed results, with some studies showing that metformin can enhance the effectiveness of chemotherapeutic drugs whilst others have shown increased chemoresistance in the presence of metformin $[19,20]$. With regards to cisplatin, metformin has been shown to reduce cisplatin sensitivity through the AMPK-independent upregulation of the Akt survival pathway [20]. A search on clinicaltrials.gov found over 40 clinical trials investigating metformin and a variety of chemotherapeutic drugs, for breast, ovarian and prostate cancer amongst a number of others.

In this study, we investigated the effect of metformin on OSCC cell proliferation and on the cytotoxicity of cisplatin for OSCC cells. We show that whilst metformin markedly reduces OSCC cell proliferation and causes cells to accumulate in the G0/G1 phase of the cell cycle, it also significantly protects against cisplatin cytotoxicity. The protective effect is not solely due to reduced cellproliferation, as the biguanide minimally to partially protects against the DNA-crosslinker, mitomycin C, but is dependent on a metformin-induced increase in glycolysis and intracellular $\mathrm{NAD}(\mathrm{P}) \mathrm{H}$ levels with a concomitant increase in reduced intracellular thiols, which coincides with decreased cisplatin-DNA adduct formation. The glutathione synthesis inhibitor buthionine sulfoximine (BSO) significantly reverses this protective effect, confirming the role of reduced glutathione in cisplatin detoxification by metformin-treated cells. In light of these findings, we investigated the copper-bis(thiosemicarbazones), copper diacetyl-bis(4-methylthiosemicarbazonato)copper(II) (Cu-ATSM) and copper glyoxal-bis (4-methylthiosemicarbazonato)copper(II) (Cu-GTSM). 
Copper-bis(thiosemicarbazones) induce cytotoxicity through a number of mechanisms, including inhibition of DNA synthesis [21]. Importantly, as these compounds are known to be trapped in cells under reducing conditions, they are therefore compatible with a reducing intracellular state [22]. We show that both Cu-ATSM and $\mathrm{Cu}-\mathrm{GTSM}$ display significant levels of cytotoxicity at $\mathrm{LD}_{50}$ values comparable to or lower than cisplatin, both alone or in combination with metformin, highlighting the use of metformin and reduction-compatible cytotoxic drugs as a novel combination therapy strategy for the treatment of OSCC.

\section{Methods}

\section{Reagents}

Reagents for flow cytometry were purchased from Beckman Coulter. All other reagents were purchased from Sigma Aldrich unless otherwise specified.

\section{Synthesis of bis(thiosemicarbazones)}

The bis(thiosemicarbazones), ATSM and GTSM, were synthesised from 4-methyl thiosemicarbazide and butanedione or glyoxal, respectively, according to the method of French et al. [23].

ATSM: ${ }^{1} \mathrm{H}$ NMR (500 MHz, DMSO) $11.74(2 \mathrm{H}, \mathrm{s}, 2 \times$ $\mathrm{CH}=\mathrm{N}), 8.48(2 \mathrm{H}, \mathrm{d}, J=4.2,2 \times \mathrm{NH}), 7.72(2 \mathrm{H}, \mathrm{s}, 2 \times$ $\mathrm{NH}), 2.96\left(6 \mathrm{H}, \mathrm{d}, J=4.4,2 \times \mathrm{CH}_{3}\right) ;{ }^{13} \mathrm{C} \mathrm{NMR}(126 \mathrm{MHz}$, DMSO $177.55(2 \times \mathrm{C}=\mathrm{S}), 140.02(2 \times \mathrm{C}=\mathrm{N}), 30.89$ $\left(2 \times \mathrm{CH}_{3}\right)$.

GTSM: ${ }^{1} \mathrm{H}$ NMR (500 MHz, DMSO) $10.20(2 \mathrm{H}, \mathrm{s}, 2 \times$ $\mathrm{NH}), 8.36(2 \mathrm{H}, \mathrm{d}, J=4.1,2 \times \mathrm{NH}), 3.02(6 \mathrm{H}, \mathrm{d}, J=4.5$, $\left.2 \times \mathrm{CH}_{3}\right), 2.20\left(6 \mathrm{H}, \mathrm{s}, 2 \times \mathrm{CH}_{3}\right) ;{ }^{13} \mathrm{C} \mathrm{NMR}(126 \mathrm{MHz}$, DMSO $178.47(2 \times \mathrm{C}=\mathrm{S}), 147.95(2 \times \mathrm{C}=\mathrm{N}), 31.18$ $\left(2 \times \mathrm{CH}_{3}\right), 11.64\left(2 \times \mathrm{CH}_{3}\right)$.

$\mathrm{Cu}$-ATSM and Cu-GTSM were synthesized from ATSM and GTSM and cupric chloride as previously described [24].

\section{Cell culture}

The human OSCC cell lines were a kind gift from Professor Robin Veale. These cells, WHCO1, WHCO5 [25] and SNO [26] were maintained in Dulbecco's Modified Eagles Medium/Hams F12 (DMEM/Hams F12, 3:1) supplemented with $10 \% \mathrm{FCS}$ at $37^{\circ} \mathrm{C}$ and $5 \% \mathrm{CO}_{2}$.

\section{Cell proliferation}

Cell proliferation was assessed by cell counts using trypan blue exclusion. Cells were seeded in 48-well plates at $1 \times 10^{4}$ cells per well. After 24 hours, cells were incubated with or without $10 \mathrm{mM}$ metformin for an additional 24 hours. Cells were then trypsinized, resuspended in $1 \times \mathrm{PBS}$ and incubated in 2\% trypan blue for 2 minutes and counted using a haemocytometer $(\mathrm{n}=5 \pm \mathrm{SD})$.

\section{Cell cycle analysis}

Cell cycle analysis was by flow cytometry as previously described [27]. Cells were seeded equally in $10 \mathrm{~cm}$ dishes and cultured for 48 hours ( $\sim 60 \%$ confluent). At this time, the medium was replaced and cells incubated with or without $10 \mathrm{mM}$ metformin for 24 hours. Control cells were serum-deprived for 8 hours. Cells were then harvested and prepared for analysis using the DNA Prep Reagent kit according to manufacturers' instructions (Beckman Coulter). Briefly, cells were treated with DNA prep LPR (lysis) solution in order to facilitate propidium iodide (PI) entry and samples vortexed for 10 seconds followed by the addition of DNA prep stain (PI and RNAse) and additional vortexing. Samples were then immediately analysed on an LSRFortessa ${ }^{\mathrm{TM}}$ cell analyser, BD Biosciences. DNA histograms were analysed using FlowJo v10 software and the percentage of cells in the G0/G1, S, and G2/M phase of the cell cycle calculated $(n=3 \pm S D)$.

\section{Cytotoxicity assays}

Cytotoxicity was assessed using the 3-(4,5-dimethylthiazol2-yl)-2,5 diphenyltetrazolium bromide (MTT) assay. Cells (8500 cells per well) were seeded into 96-well plates and after 24 hours exposed to cytotoxic agents for varying times. After treatment, the medium was replaced with $100 \mu \mathrm{l}$ of MTT solution $(0.5 \mathrm{mg} / \mathrm{ml}$ in cell culture medium) and incubated at $37^{\circ} \mathrm{C}$ for 2 hours. MTT solution was then removed, and MTT formazan dissolved in $100 \mu$ l dimethyl sulfoxide (DMSO). Absorbance was measured at $570 \mathrm{~nm}$ using the Bio-Rad iMark microplate reader $(n=3 \pm S D)$.

\section{ICP-MS analysis of platinum-DNA adducts}

Inductively-coupled plasma mass spectrometry (ICPMS) was performed as previously described [28]. Briefly, cells were treated with cisplatin ( $\mathrm{LD}_{30}$ concentrations) for 48 hours with or without 24 hour prior exposure to $10 \mathrm{mM}$ metformin. Total genomic DNA was extracted, resuspended in water and quantified using a NanoDrop ND-1000 spectrophotometer (Thermo Scientific). DNA samples were hydrolysed in a final concentration of $1 \%$ $\mathrm{HNO}_{3}$ at $70^{\circ} \mathrm{C}$ for 24 hours and analysed for platinum $(\mathrm{n}=3 \pm \mathrm{SD})$ on an Agilent 7700 ICP-MS. The instrument was optimised for sensitivity and low oxides. Analysis was done in no-gas mode, and the instrument was calibrated for platinum analysis using National Institute of Standards and Technology traceable standards.

\section{Determination of glycolysis via lactate production}

As an indicator of levels of glycolysis, lactate levels in culture medium were quantified using a lactate dehydrogenase assay [29] where the production of NADH from NAD via the conversion of lactate to pyruvate is directly proportional to lactate concentration. Cells were seeded and treated as for cell cycle analysis and both conditioned 
culture medium and cells collected after 24 hours. Cells were counted using trypan blue exclusion as described above. For lactate quantification, $50 \mu \mathrm{l}$ of medium was added to $950 \mu \mathrm{l}$ glycine-hydrazine buffer (0.64 M glycine, $0.64 \mathrm{M}$ hydrazine, $4.8 \mathrm{mM} \mathrm{NAD}{ }^{+}, 16 \mathrm{U} / \mathrm{ml}$ lactate dehydrogenase, $\mathrm{pH}$ 9.2) and incubated at $37^{\circ} \mathrm{C}$ for 2 minutes. $\mathrm{NADH}$ was then quantified spectrophotometrically at $340 \mathrm{~nm}$ and values corrected for cell number $(\mathrm{n}=3 \pm \mathrm{SD})$.

\section{Quantification of reducing equivalents}

Total cellular reducing equivalents were quantified by tetrazolium (MTT) assay as previously described [30]. An equal number of cells were seeded into 96 -well plates (8500 cells per well) and after 24 hours cells were incubated for 24 hours with or without $10 \mathrm{mM}$ metformin and MTT assay performed. Values were corrected for cell number using trypan blue exclusion as described above $(n=3 \pm S D)$.

A

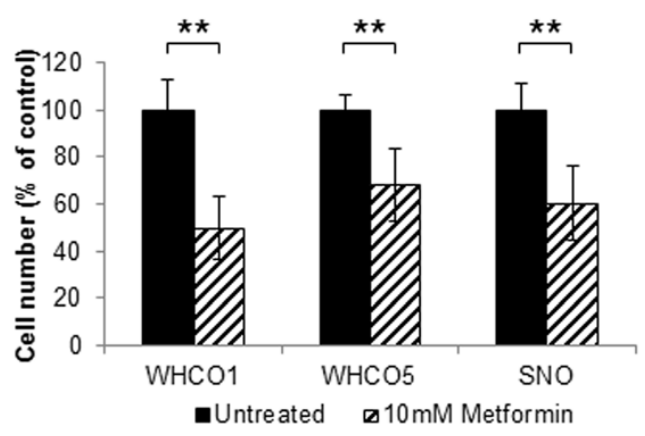

B

\begin{tabular}{|c|c|c|c|}
\hline & & \multicolumn{2}{|c|}{$\%$ of cells at cell cycle phase } \\
\hline & & Untreated & Metformin \\
\hline \multirow[t]{3}{*}{ WHCO1 } & G0/G1 & $50.8 \pm 1.4 \%$ & $62.8 \pm 3.3 \%$ \\
\hline & $\mathrm{S}$ & $33.1 \pm 3.4 \%$ & $23.5 \pm 1.9 \%$ \\
\hline & $\mathrm{G} 2 / \mathrm{M}$ & $15.1 \pm 2.7 \%$ & $12.7 \pm 1.2 \%$ \\
\hline \multirow[t]{3}{*}{ WHCO5 } & G0/G1 & $52.8 \pm 3.0 \%$ & $60.9 \pm 5.3 \%$ \\
\hline & $\mathrm{S}$ & $30.5 \pm 0.6 \%$ & $21.6 \pm 4.7 \%$ \\
\hline & $\mathrm{G} 2 / \mathrm{M}$ & $15.4 \pm 2.9 \%$ & $16.5 \pm 1.8 \%$ \\
\hline \multirow[t]{3}{*}{ SNO } & G0/G1 & $62.6 \pm 3.0 \%$ & $73.9 \pm 4.0 \%$ \\
\hline & $\mathrm{S}$ & $24.1 \pm 4.5 \%$ & $16.4 \pm 5.2 \%$ \\
\hline & $\mathrm{G} 2 / \mathrm{M}$ & $13.2 \pm 4.9 \%$ & $8.8 \pm 2.9 \%$ \\
\hline
\end{tabular}

C
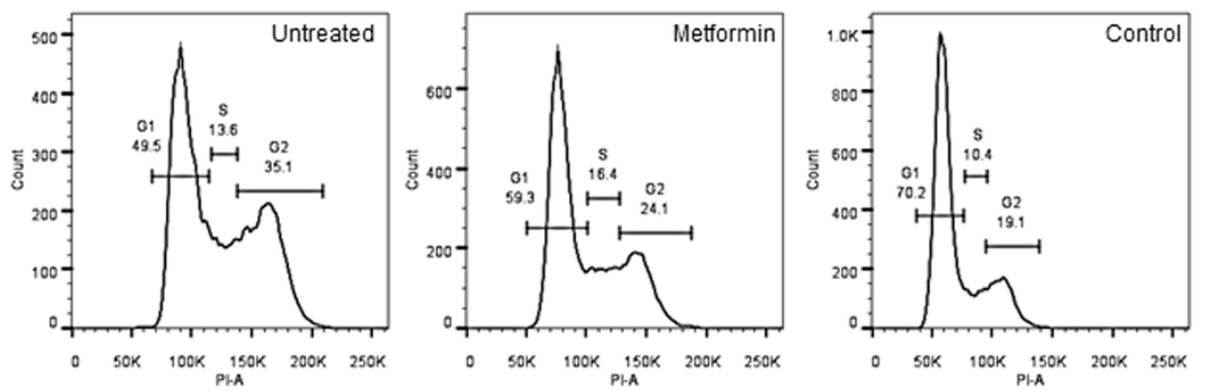

Figure 1 Anti-proliferative effects of metformin on OSCC cells. A, Cells exposed to $10 \mathrm{mM}$ metformin for 24 hours showed a decrease in cell number in comparison to untreated controls across all cell lines, $n=4$, mean \pm SD. B, Quantification and C,representative figures of flow cytometry analysis (from SNO cells) for untreated cells (Untreated), FCS deprived control (FCS Control) and cells exposed to $10 \mathrm{mM}$ metformin for 24 hours (Metformin). Metformin treated cells exhibited an accumulation at the G0/G1 stage of the cell cycle across all cell lines, expressed as \% of cells in phase of cell cycle $(n=3$, mean $\pm S D)$, where for all cells there was a statistically significant increase in cells in G0/G1 in metformin treated cells relative to untreated controls with WHCO1 $p=0.05$, WHCO5 $p=0.04$ and SNO $p=0.01$. 

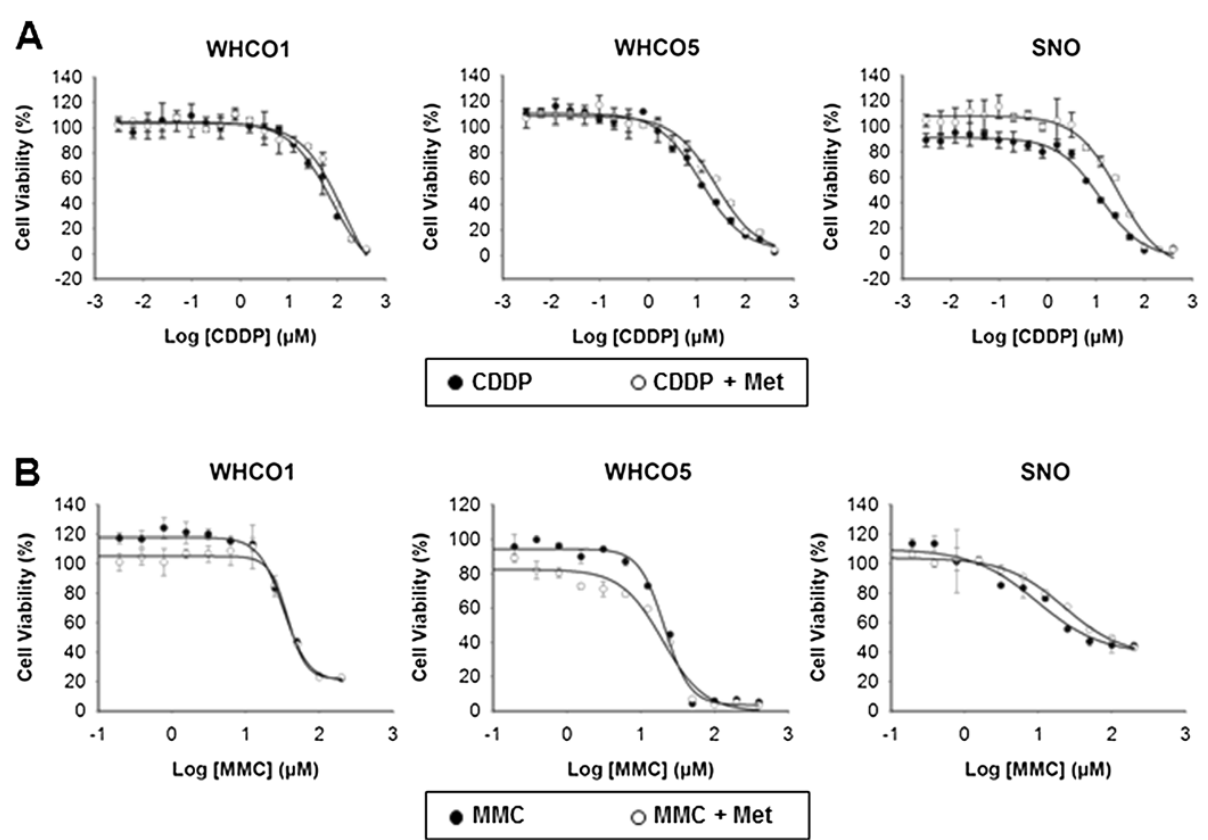

Figure 2 Effect of metformin on cisplatin and mitomycin C cytotoxicity for OSCC cells. OSCC cells, untreated or treated with $10 \mathrm{mM}$ metformin for 24 hours and then treated with (A) cisplatin or (B) mitomycin C for a further 48 hours, were assessed by MTT assay. All metformin-cisplatin treated cells displayed a trend for higher $L_{50}$ values, with WHCO1 and SNO cells statistically higher $(n=3, m e a n \pm S D)$.

\section{Low-molecular weight thiol quantification}

Total low-molecular weight thiols were quantified using monobromobimane, which forms fluorescent thiol conjugates [31]. Cells were seeded and treated as for cell cycle analysis with or without $10 \mathrm{mM}$ metformin for 24 hours. Cells were subsequently washed three times with $1 \times \mathrm{PBS}$ and incubated in $1 \mathrm{ml}$ of $1 \times \mathrm{PBS}$ with $18 \mu \mathrm{l}$ monobromobimane solution (stock $5 \mathrm{mg} / \mathrm{ml}$ in DMSO) for 10 minutes. Cells were then lysed in $1 \mathrm{ml}$ of triple detergent lysis buffer (50 mM Tris- $\mathrm{HCl}, 150 \mathrm{mM} \mathrm{NaCl}$, $0.1 \%$ SDS, $1 \%$ Triton $\times-100,0.5 \%$ sodium deoxycholate), the lysate centrifuged at $10000 \mathrm{~g}$ and $100 \mu \mathrm{l}$ of the resultant supernatant fluorescently analysed at $360 \mathrm{~nm}_{\text {excita- }}$ tion $/ 460 \mathrm{~nm}_{\text {emission }}$ using an Ascent multi-well plate fluorimeter (Thermo Scientific). Cells seeded in parallel dishes were counted using trypan blue exclusion as above and fluorescence values were corrected for cell number $(\mathrm{n}=3 \pm \mathrm{SD})$.

\section{Glutathione depletion assay}

The glutathione synthesis inhibitor BSO was used in order to deplete intracellular glutathione levels and thereby assess the involvement of thiols (glutathione) in the cytoprotective effects of metformin on cisplatin toxicity [32]. Cytotoxicity assays were performed as above with the following modifications, cells were seeded at 7500 cells per well in 96-well plates and allowed to settle for 18 hours. Cells were then treated with $0.4 \mathrm{mM}$ of BSO for 18 hours, followed by the addition of $10 \mathrm{mM}$ metformin (or metformin diluent for control cells) and subsequently cisplatin, and cytotoxicity determined by MTT assay as above $(n=3 \pm S D)$.

Table 1 Cytotoxicity in OSCC cells treated with or without metformin and cisplatin or mitomycin C

\begin{tabular}{|c|c|c|c|c|c|c|}
\hline \multirow{3}{*}{$\begin{array}{l}\text { Compounds } \\
\text { Cisplatin }\end{array}$} & \multicolumn{6}{|c|}{$\mathrm{LD}_{50}(\mu \mathrm{M})$} \\
\hline & \multicolumn{2}{|c|}{ WHCO1 } & \multicolumn{2}{|c|}{ WHCO5 } & \multicolumn{2}{|c|}{ SNO } \\
\hline & $70.88 \pm 13.8$ & \multirow{2}{*}{$p=0.009$} & $11.68 \pm 3.62$ & $p=0.075$ & $11.01 \pm 1.62$ & \multirow{2}{*}{$p=0.000$} \\
\hline Met + Cisplatin & $126.02 \pm 26.57$ & & $28.03 \pm 15.81$ & & $28.16 \pm 3.37$ & \\
\hline Mitomycin C & $32.73 \pm 2.49$ & \multirow{2}{*}{$p=0.003$} & $32.87 \pm 3.03$ & $p=0.25$ & $9.92 \pm 1.80$ & \multirow{2}{*}{$p=0.011$} \\
\hline Met + Mitomycin C & $37.15 \pm 0.79$ & & $30.19 \pm 4.36$ & & $16.64 \pm 2.77$ & \\
\hline
\end{tabular}




\section{Statistical analysis}

Comparisons were by two-tailed Student's t-tests and $\mathrm{p}<0.05$ was considered statistically significant. $\mathrm{LD}_{50}$ and $\mathrm{LD}_{30}$ values were calculated using GraphPad Prism version 6 .

\section{Results}

OSCC cells exhibit decreased cell proliferation and cell cycle arrest in response to metformin

We investigated the effect of metformin on three OSCC cell lines (WHCO1, WHCO5 and SNO), previously derived from South African OSCC patients [25,26]. All cell lines exhibited a significant reduction in cell proliferation in response to $10 \mathrm{mM}$ metformin after 24 hour treatment, in comparison to untreated controls. There was $50 \%$, $32 \%$ and $39 \%$ reduction in cell proliferation in WHCO1, WHCO5 and SNO cells, respectively (Figure 1A). In addition, we assessed cell cycle progression using flow cytometry with propidium iodide staining of cellular DNA content. Cells deprived of foetal calf serum (FCS) for 8 hours were used as the control, which as expected, showed an increase in the number of cells in G0/G1 phase of the cell cycle. Metformin treatment $(10 \mathrm{mM}$ for 24 hours), as anticipated, caused an increase in the number of cells in G0/G1 phase relative to untreated controls (Figure $1 \mathrm{~B}$ and $\mathrm{C}$ ).

\section{Metformin protects cells from cisplatin cytotoxicity}

Next, we assessed the effect of metformin on cisplatin cytotoxicity by MTT assay. Cells pre-treated with $10 \mathrm{mM}$ metformin for 24 hours and then treated with $10 \mathrm{mM}$ metformin and cisplatin for 48 hours (Figure 2A), exhibited significantly lower cytotoxicity than cells

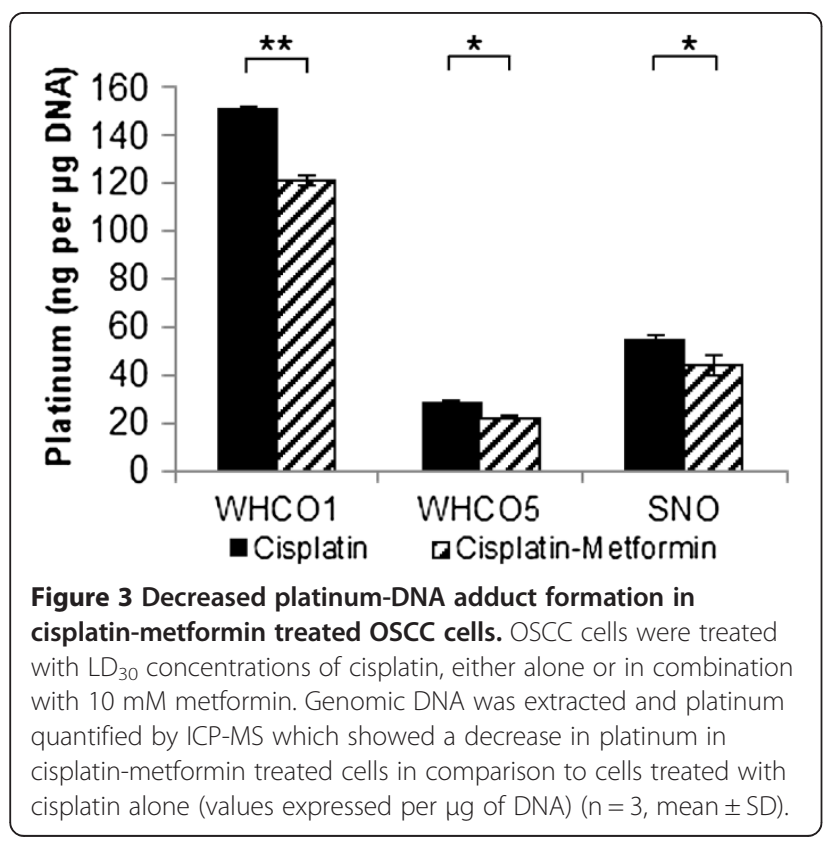

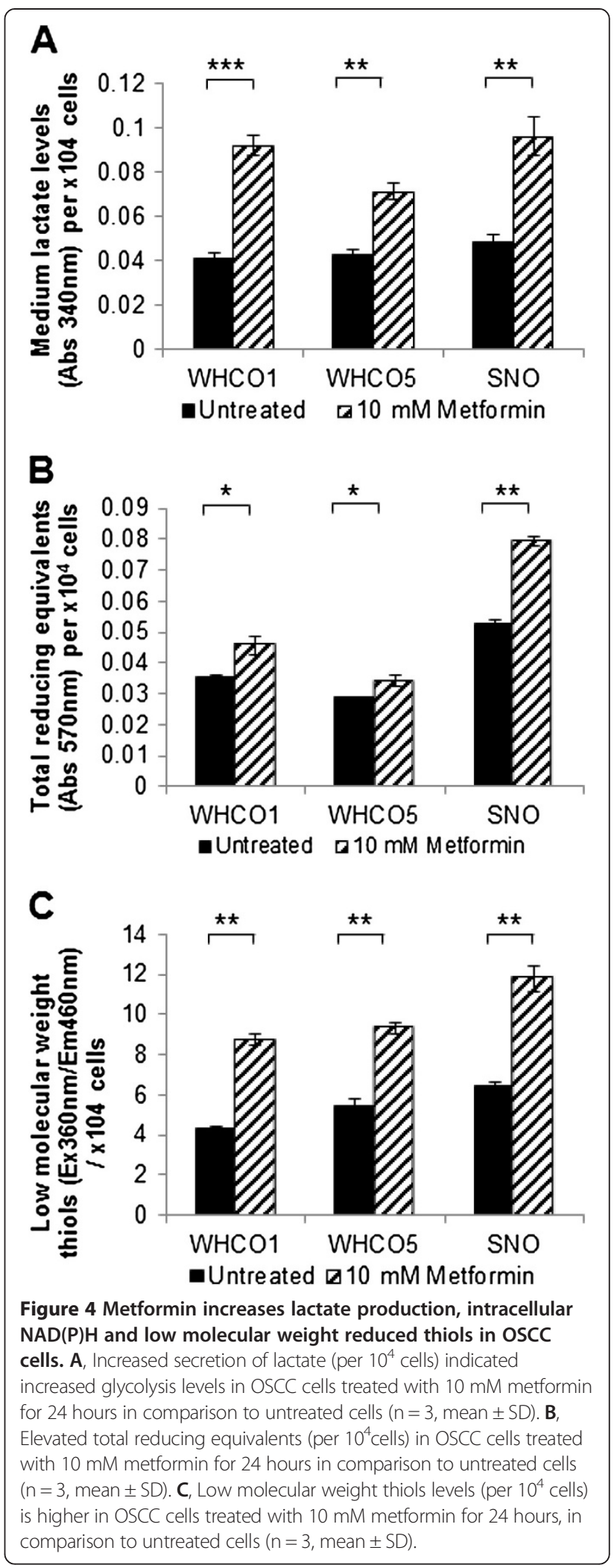


treated with cisplatin alone; thus displaying higher $\mathrm{LD}_{50}$ values for cisplatin in the presence of metformin, with a $78 \%$ increase for WHCO1, 140\% increase for WHCO5 and $156 \%$ increase for SNO cells (Table 1). We assessed the effects of metformin on the formation of cisplatin-DNA adducts, by treating cells as above but using the calculated $\mathrm{LD}_{30}$ of cisplatin. DNA-bound platinum, as quantified by ICP-MS, showed a significant reduction in metformin treated cells by $19.3 \%$ in WHCO1, $14.1 \%$ in WHCO5 and $18.4 \%$ in SNO cells (Figure 3 ). To determine whether reduced cytotoxicity and cisplatin-DNA adduct levels was principally due to the observed metformin-induced reduction in cell proliferation, cells were treated with an alternative DNA crosslinker, mitomycin $\mathrm{C}$ with or without metformin as above (Figure 2B). Partial to no protection from mitomycin $\mathrm{C}$ was observed after metformin pre-treatment across the cell lines (Table 1), indicating that factors other than decreased proliferation were the major contributors to metformin-dependent cisplatin resistance.

\section{Metformin treatment increases lactate production, intracellular $\mathrm{NAD}(\mathrm{P}) \mathrm{H}$ and low molecular weight reduced thiols in OSCC cells}

Metformin has been shown to increase cellular glucose transport and glycolytic rates [33]. We hypothesized that such an occurrence in OSCC cells could result in an enhanced intracellular reducing environment (increased $\mathrm{NAD}(\mathrm{P}) \mathrm{H}$ levels) and the potential for increased intracellular reduced thiol levels, thus contributing to the observed metformin-induced protection against cisplatin. Cisplatin cytotoxicity has been previously shown to be antagonized by low-molecular-weight reduced thiols via cisplatin-thiol adduct formation, specifically with glutathione. Glutathione is the major contributor to intracellular thiols, existing in millimolar amounts in the cytosol $[7,8,34]$. We found that glycolysis (as measured by lactate output), and indirectly, glucose utilization, was indeed significantly increased for all OSCC cell lines after treatment with $10 \mathrm{mM}$ metformin for 24 hours relative to untreated controls (Figure 4A). As predicted, total intracellular $\mathrm{NAD}(\mathrm{P}) \mathrm{H}$ levels (quantified by tetrazolium (MTT) reduction) (Figure 4B) and low-molecular weight thiol levels (monobromobimane-thiol adduct fluorescence) (Figure 4C) were significantly elevated for all OSCC cell lines following metformin treatment relative to untreated controls.

\section{Intracellular thiols mediate metformin induced cisplatin protection in OSCC cells}

To confirm that increased thiol levels can protect OSCC cells against cisplatin, cells were treated with the cell permeable thiol derivative, $\mathrm{N}$-acetyl cysteine (NAC) $(10 \mathrm{mM})$ prior to cisplatin exposure [35]. Predictably, all OSCC cell lines were significantly protected against cisplatin cytotoxicity by NAC pre-treatment (Figure 5). Therefore, our hypothesis, that a metformin-dependent increase in intracellular thiols is primarily responsible for the observed protection against cisplatin, seemed highly plausible. Since glutathione is the major thiol species within the cells, we confirmed its role in metformin-induced cisplatin resistance using the glutathione synthase inhibitor, BSO [32], to deplete intracellular glutathione pools. Cells were treated with metformin in the presence of $\mathrm{BSO}$, prior to cisplatin exposure. Glutathione depletion by BSO almost completely reversed the protective effect of metformin for all OSCC cell lines, confirming the role of reducedglutathione in metformin-induced cisplatin resistance (Figure 6). We also observed that BSO increased cisplatin cytotoxicity, with lower $\mathrm{LD}_{50}$ values, and this was anticipated as decreased intracellular glutathione levels would result in less cisplatin-thiol sequestration and an increase in cisplatin-DNA adduct formation.

\section{OSCC cells are highly susceptible to copper-bis (thiosemicarbazones)}

Given the above observations, we considered the role of cytotoxic molecules that are compatible with increased
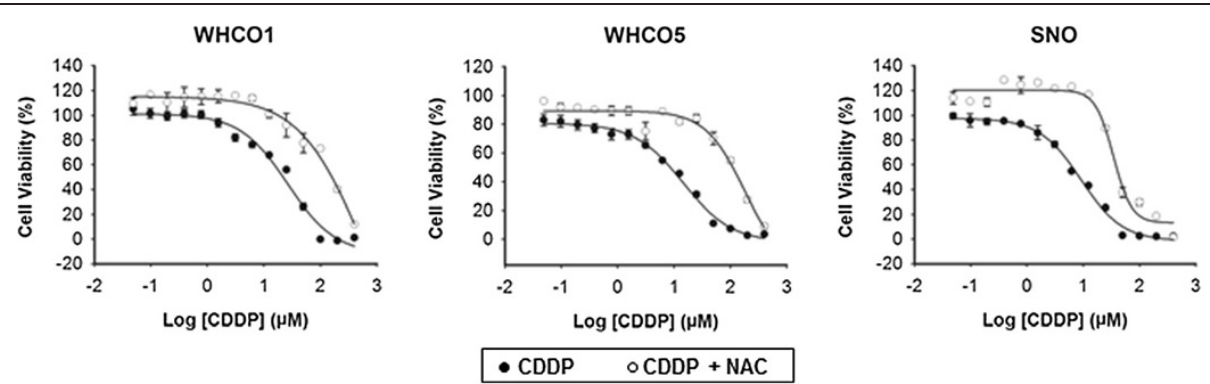

Figure $\mathbf{5}$ Increased intracellular thiols causes cisplatin resistance in OSCC cells. The cell permeable thiol derivative NAC was used to confirm the role of thiols in cisplatin resistance in OSCC cells. Cells were either untreated or treated with 10 mM NAC for 24 hours and then treated with a concentration range of cisplatin for a further 48. Cytotoxicity was assessed by MTT assay. All NAC-cisplatin treated cells displayed higher $\mathrm{LD}_{50}$ values than cisplatin treated cells alone $(n=3$, mean $\pm S D)$. 


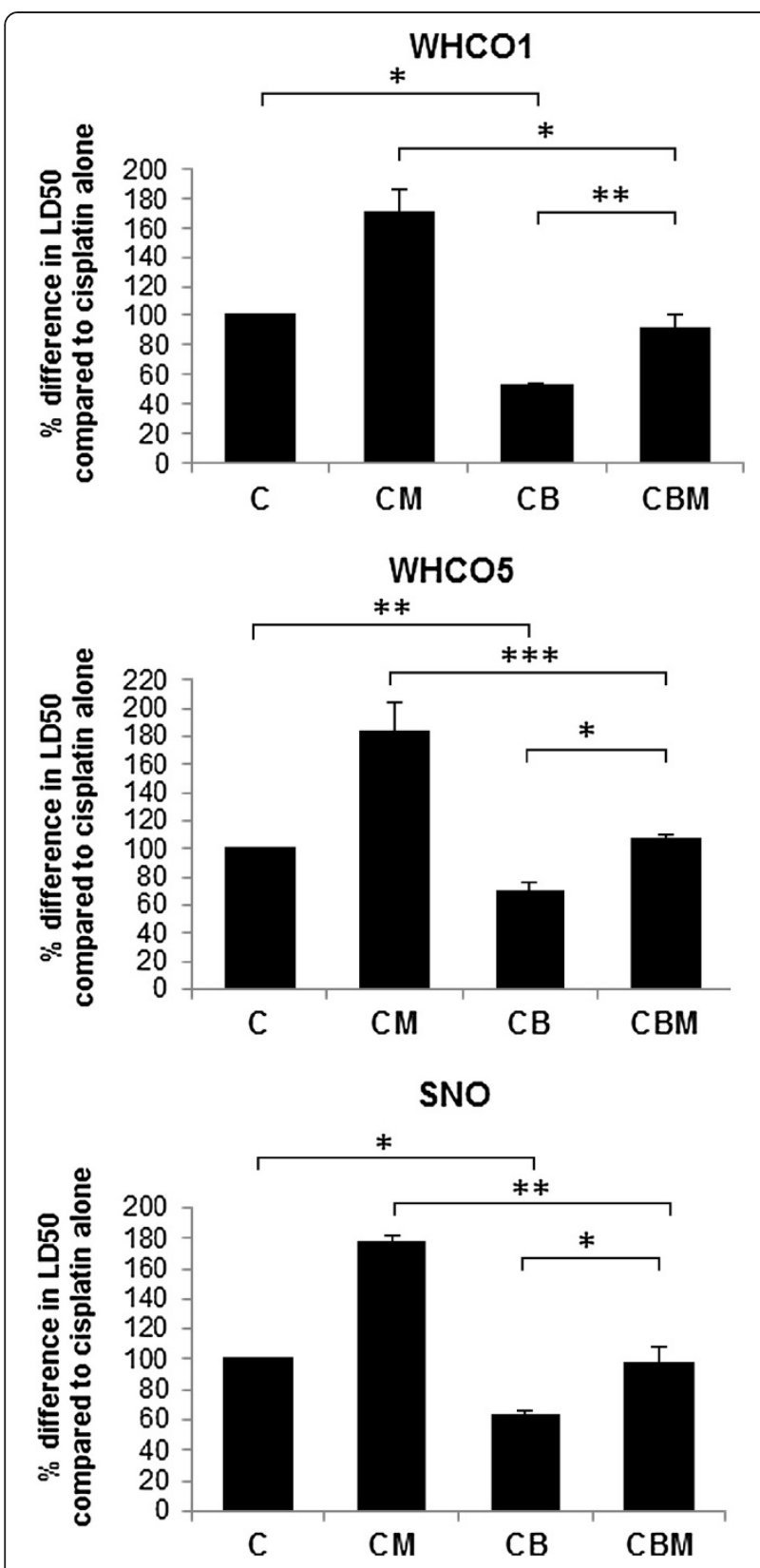

Figure 6 Metformin-induced cisplatin resistance is reversed by glutathione depletion in OSCC cells. The glutathione synthesis inhibitor, BSO was used to confirm the involvement of elevated glutathione levels in metformin induced cisplatin resistance in OSCC cells. MTT assays for cytotoxicity were performed as described, with cells treated with cisplatin alone (C), or in the presence $0.4 \mathrm{mM} \mathrm{BSO}$ (CB), or metformin and cisplatin (CM), or metformin and cisplatin in the presence of $0.4 \mathrm{mM} \mathrm{BSO}(\mathrm{CMB})$. Data is expressed as the percentage difference of $L D_{50}$ values for each treatment relative to cisplatin alone $(n=3$, mean $\pm S D)$. Predictably, the inhibition of glutathione synthesis increased cisplatin toxicity as $L_{50}$ values for cisplatin-BSO treated cells were significantly lower than cisplatin alone. Importantly, the presence of the inhibitor ablates the protective effect of metformin, with $\mathrm{LD}_{50}$ values for cisplatin-metfomin-BSO treated cells approaching those of cisplatin alone. intracellular reducing conditions and could therefore be used in conjunction with metformin. In this way, the cytostatic effects of metformin could be utilised when combined as an adjuvant in chemotherapy regimens; since there is also evidence that metformin targets cancer stem cells, this would offer a considerable added advantage [18]. The copper bis(thiosemicarbazone) derivatives ATSM and GTSM have been previously shown to be trapped intracellularly under reducing conditions [22]. We therefore tested their efficacy as cytotoxic agents against OSCC cell lines with or without metformin. OSCC cells were pre-treated with or without $10 \mathrm{mM}$ metformin for 24 hours and then treated with copper-bis(thiosemicarbazones) and $10 \mathrm{mM}$ metformin for 48 hours (Figure 7). Interestingly, we found that both $\mathrm{Cu}$-ATSM and Cu-GTSM displayed significant cytotoxicity for all cell lines, both in the presence and absence of metformin treatment, with $\mathrm{LD}_{50}$ values lower than or comparable to cisplatin alone. Cu-GTSM displayed lower $\mathrm{LD}_{50}$ levels than Cu-ATSM (Table 2). Statistically there was no difference between untreated and metformin treated samples $(p>0.05)$. Non-cop per-conjugated bis(thiosemicarbazone) compounds displayed far lower levels of cytotoxicity than their copperconjugated counterparts, with $\mathrm{LD}_{50}$ concentrations over $200 \mu \mathrm{M}$; copper alone had minimal effect on cells at the concentrations used in this study.

\section{Discussion}

We have established that metformin significantly reduces the proliferation of OSCC cells. However, we observed that metabolic alterations caused by metformin rendered cells less sensitive to the commonly used chemotherapeutic agent, cisplatin. Previous studies have shown that metformin can reduce sensitivity to cisplatin through the activation of pro-survival signals via Akt [20] and hyperactivation of Akt has been linked to increased glycolysis [36]. Those studies therefore support our findings, which show that metformin increases glycolysis with a subsequent increase in intracellular reducing equivalents and a concomitant increase in intracellular reduced thiols.

Since cisplatin is ineffective in a reducing intracellular environment, our findings also support observations regarding cisplatin chemoresistance in tumours; cancer cells within the tumour are known to display a highly reducing phenotype and resist cisplatin chemotherapy [37]. However, in recent years, the observation that tumours consist of cells in differing metabolic states to surrounding normal tissue [38] has encouraged the concept of cancer-cell specific metabolic targeting as an increasingly popular strategy in cancer therapy [39]. Our study highlights the use of metformin with cytotoxic agents that are compatible with or remain active under 

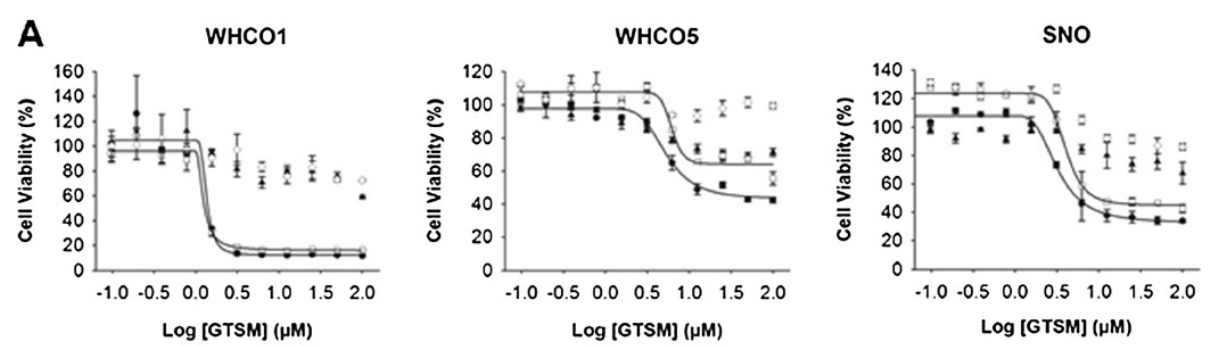

- Cu-GTSM $\triangle$ GTSM 口CU-GTSM+Met $\diamond$ GTSM+Met
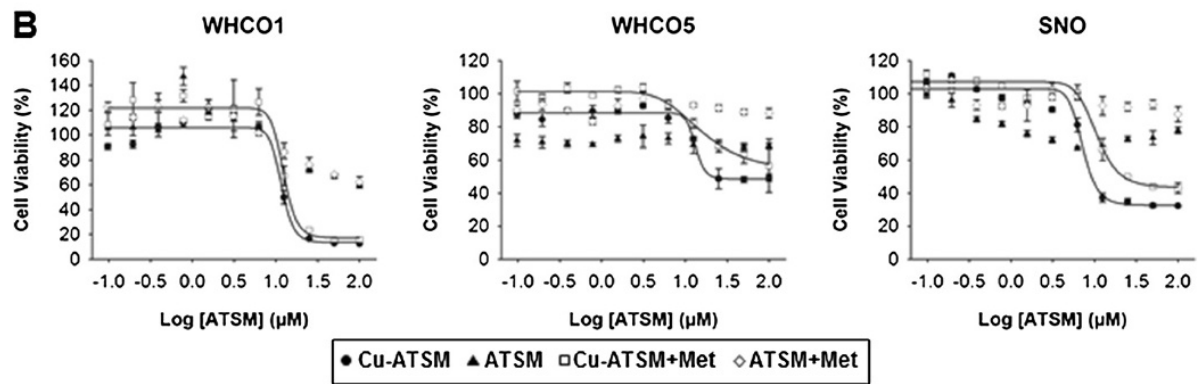

Figure 7 Copper bis(thiosemicarbazones) are highly toxic to OSCC cells in the presence of metformin. OSSC cells, untreated or treated with $10 \mathrm{mM}$ metformin for 24 hours and then treated with (A) GTSM or Cu-GTSM, or (B) ATSM or Cu-ATSM for a further 48 hours were assessed by MTT assay. The non-copper-conjugated bis(thiosemicarbazones) showed relatively little toxicity with $L_{50}$ values greater than $200 \mu M$ in both the presence and absence of metformin. The copper-conjugated compounds however displayed considerable toxicity to OSCC cells with similar $\mathrm{LD}_{50}$ values for metformin treated-and untreated compounds for WHCO1, WHCO5, and SNO cells.

reducing conditions, thus paving the way for novel drug therapy combinations for the treatment of this highly aggressive malignancy.

Mitomycin C, which must be reductively activated to exert its biological effects [40], is one potential candidate for this strategy as partial to no protection from this drug was observed after metformin pre-treatment. However, an obvious concern with the use of mitomycin $C$ and related DNA crosslinkers in combination with metformin would be the potential for decreased drug effectiveness or the emergence of drug resistance in vivo, due to

Table 2 Cytotoxicity in OSCC cells treated with or without metformin and with Cu-GTSM or Cu-ATSM

\begin{tabular}{lccc}
\hline Compounds & \multicolumn{3}{c}{ LD $_{\mathbf{5 0}}(\boldsymbol{\mu M})$} \\
\cline { 2 - 4 } & WHCO1 & WHCO5 & SNO \\
\hline Cu-GTSM & $1.14 \pm 0.16$ & $5.39 \pm 0.9$ & $3.37 \pm 0.23$ \\
Metformin + CU-GTSM & $1.16 \pm 0.12$ & $6.24 \pm 0.01$ & $4.23 \pm 0.7$ \\
GTSM & $>200$ & $>200$ & $>200$ \\
Metformin + GTSM & $>200$ & $>200$ & $>200$ \\
Cu-ATSM & $11.93 \pm 0.47$ & $13.51 \pm 0.81$ & $7.099 \pm 0.57$ \\
Metformin + Cu-ATSM & $12.54 \pm 0.19$ & $12.05 \pm 0.83$ & $10.90 \pm 0.77$ \\
ATSM & $>200$ & $>200$ & $>200$ \\
Metformin + ATSM & $>200$ & $>200$ & $>200$ \\
\hline OSCC cells were
\end{tabular}

OSCC cells were treated with $10 \mathrm{mM}$ metformin and either GTSM, Cu-GTSM, ATSM or Cu-ATSM and the MTT assay performed. $\mathrm{LD}_{50}(\mu \mathrm{M})$ was calculated on replicates $(n=3$, mean $\pm S D)$. the anti-proliferative effects of the biguanide. Therefore, agents that are either reductively activated or tolerant, and that target proliferating and non-proliferating tumour cells, would be a more logical choice for use in combination with metformin in OSCC. We have established that a potential highly efficacious combination strategy of this kind, could be metformin and the copper-bis (thiosemicarbazones), Cu-GTSM or Cu-ATSM. Bis (thiosemicarbazones) have been considered for cancer treatment since the 1950's [23], whilst the copper-bis (thiosemicarbazones) have been shown to possess potent anti-cancer activities and are attractive candidates for use as chemotherapeutics as they often preferentially accumulate in tumour tissue and are retained in cells under reducing conditions [22]. We have shown that $\mathrm{Cu}$-ATSM and Cu-GTSM, in contrast to non-copper conjugated bis(thiosemicarbazones), are highly cytotoxic to OSCC cells, both in the presence and absence of metformin, and are thus metformin-compatible. The fact that an increase in toxicity was not observed for Cu-ATSM or $\mathrm{Cu}-\mathrm{GTSM}$ in the presence of metformin suggests that: (1) there already exists a sufficiently high intracellular reducing environment in the OSCC cell lines used (a common observation in cancer cells [37]) to allow for the intracellular accumulation of these compounds to toxic levels, and (2) that the mechanisms of toxicity of these compounds, are compatible with, but not necessarily dependent on a intracellular reducing environment. 
Predictably we found that $\mathrm{Cu}$-GTSM exhibited lower $\mathrm{LD}_{50}$ values than $\mathrm{Cu}-\mathrm{ATSM}$ as $\mathrm{Cu}-\mathrm{GTSM}$ is known to be rapidly reduced by intracellular thiols resulting in cell retention, copper release and ultimately apoptosis via oxidative stress, and/or the inhibition of DNA synthesis and oxidative phosphorylation [41,42]; $\mathrm{Cu}$-ATSM on the other hand has been shown to be poorly reduced by intracellular thiols and thought to be maintained in a reduced state (and thus retained intracellularly) only under hypoxic conditions [41]. Recently, however, Donnelly et al. have shown that Cu-ATSM can be retained in cells under normoxic conditions when the intracellular reducing environment is increased due to factors such as impaired mitochondrial electron transport chain function [22]. These findings appear to agree with the findings of our study as SNO cells, which exhibit the greatest intracellular reducing environment (in the absence of metformin) of all the OSCC cell lines tested (Figure 4B), exhibit the greatest sensitivity to $\mathrm{Cu}$-ATSM (Table 2). Nonetheless, the fact that all OSCC cell lines were highly sensitive to $\mathrm{Cu}$-ATSM alone or in combination with metformin, at $\mathrm{LD}_{50}$ values comparable to or lower than those for cisplatin for all OSCC cell lines used, is extremely promising given its increased stability over Cu-GTSM and investigatory Food and Drug Administration approval of ${ }^{64} \mathrm{Cu}$-ATSM for use as a hypoxia contrast agent [43].

\section{Conclusions}

Metformin, which has an extensive track record and is well tolerated by individuals, has been shown to suppress cancer cell proliferation. We have established that metformin significantly reduces cell proliferation in OSCC cell lines. However, we found metformin causes resistance to cisplatin in OSCC cell lines and as such we advise that caution be used when administering cisplatin to diabetic patients treated with metformin and in the use of metformin as an adjuvant to cisplatin chemotherapy. Furthermore, we have shown that two copper-conjugated bis(thiosemicarbazones), Cu-ATSM and $\mathrm{Cu}-\mathrm{GTSM}$, exhibit marked cytotoxicity in OSCC cells in the presence of metformin. The preliminary data presented in this study justifies further investigations into the therapeutic effects of copper-bis(thiosemicarbazones) in both the presence and absence of metformin, for OSCC. In addition metformin lends itself to combination therapy with reduction compatible or activated compounds (unlike cisplatin) for both OSCC and potentially other cancers where similar metabolic changes are observed.

\section{Abbreviations}

BSO: Buthionine sulfoximine; Cu-ATSM: Copper diacetyl-bis(4-methylthiosemicarbazonato)copper(II); Cu-GTSM: Copper glyoxal-bis(4-methylthiosemicarbazonato)copper(II); DMSO: Dimethyl Sulfoxide; FCS: Foetal calf serum;
ICP-MS: Inductively coupled plasma mass spectrometry; LDH: Lactate dehydrogenase; NAC: N-acetyl-L-cysteine; MTT: 3-(4,5-dimethylthiazol-2-yl)-2,5 diphenyltetrazolium bromide.

\section{Competing interests}

Authors LHD and DMD are co-applicants on a patent for the treatment of cancer and OSCC using metformin and copper-conjugated compounds. The authors declare that they have no competing interests.

\section{Authors' contributions}

LHD conceived the study, participated in its design, performed low-molecular weight thiol quantification, synthesized bis(thiosemicarbazone) compounds, conducted data analysis and interpretation, and assisted in drafting the manuscript; RJ carried out the cell proliferation studies, cell cycle analysis, prepared samples for ICP-MS analysis, and contributed to the MTT and LDH assays and statistical analysis; AR assessed bis(thiosemicarbazone) structures by NMR spectroscopy; RV participated in manuscript preparation; DMD conceived the study, participated in its design, acquired data for the MTT, LDH, thiol, reducing equivalents, and glutathione depletion assays, conducted data analysis and interpretation, and drafted the manuscript. All authors read and approved the final manuscript.

\section{Acknowledgements}

This research was supported by the University of the Witwatersrand, Johannesburg; Cancer Association of South Africa (CANSA) with a grant to DMD; and the National Research Foundation (NRF) of South Africa with grants to DMD (Grant Numbers 90710 and 91533). Any opinion, findings and conclusions or recommendations expressed in this material are those of the author(s) and neither CANSA nor the NRF accept liability in regard thereto. $\mathrm{RJ}$ is supported by a NRF PhD Innovations Bursary. LHD is funded by the Medical Research Council of South Africa; RBV is funded by the NRF, ALR is funded by the Medical Research Council of South Africa, but funding of these authors did not support this study. We thank Riana Rossouw for conducting the ICP-MS analysis at the Central Analytical Facility, Stellenbosch University, Patti Kay and Dr Sharon Shalekoff for assistance with flow cytometry and analysis, and Elsabé Scott for maintenance of cell cultures. We thank Professor Humphrey Hodgson for critical review of this manuscript.

\section{Author details}

${ }^{1}$ School of Pathology, Faculty of Health Sciences, University of the Witwatersrand, 7 York Road, Parktown, Johannesburg 2193, South Africa. ${ }^{2}$ Cell Biology Group, Centre for HIV and STI's, National Institute for Communicable Diseases, Private Bag X4, Sandringham, Johannesburg 2131, South Africa. ${ }^{3}$ School of Molecular and Cell Biology, University of the Witwatersrand, Private Bag X3, Johannesburg 2050, South Africa. ${ }^{4}$ Molecular Sciences Institute, School of Chemistry, University of the Witwatersrand, Private Bag X3, Johannesburg 2050, South Africa.

Received: 29 January 2014 Accepted: 23 April 2014

Published: 5 May 2014

\section{References}

1. Ferlay J, Shin H-R, Bray F, Forman D, Mathers C, Parkin DM: Estimates of worldwide burden of cancer in 2008: GLOBOCAN 2008. Int/ J Cancer 2008 2010(127):2893-917.

2. Enzinger PC, Mayer RJ: Esophageal cancer. N Engl J Med 2003, 349:2241-52.

3. Holmes RS, Vaughan TL: Epidemiology and pathogenesis of esophageal cancer. Semin Radiat Oncol 2007, 17:2-9.

4. La Vecchia C, Bosetti C, Lucchini F, Bertuccio P, Negri E, Boyle P, Levi F: Cancer mortality in Europe, 2000-2004, and an overview of trends since 1975. Ann Oncol 2010, 21:1323-60.

5. Stoner GD, Gupta A: Etiology and chemoprevention of esophageal squamous cell carcinoma. Carcinogenesis 2001, 22:1737-1746.

6. Ilson DH: Esophageal cancer chemotherapy: recent advances. Gastrointest Cancer Res 2008, 2:85-92

7. Siddik $\mathrm{ZH}$ : Cisplatin: mode of cytotoxic action and molecular basis of resistance. Oncogene 2003, 22:7265-7279.

8. Arn'er ESJ, Nakamura H, Sasada T, Yodoi J, Holmgren A, Spyrou G: Analysis of the inhibition of mammalian thioredoxin, thioredoxin reductase, and glutaredoxin by cis-diamminedichloroplatinum (II) and its major 
metabolite the glutathione-platinum complex. Free Rad Biol Med 2001, 31(10):1170-1178.

9. Ishikawa T: The ATP-dependent glutathione S-conjugate export pump. Trends Biochem Sci 1992, 17:463-468.

10. Tew WP, Kelsen DP, Ilson DH: Targeted therapies for esophageal cancer. Oncologist 2005, 10:590-601.

11. Kitabchi AE, Temprosa M, Knowler WC, Kahn SE, Fowler SE, Haffner SM, Andres R, Saudek C, Edelstein SL, Arakaki R, Murphy MB, Shamoon H: Role of insulin secretion and sensitivity in the evolution of type 2 diabetes in the diabetes prevention program: effects of lifestyle intervention and metformin. Diabetes 2005, 54:2404-2414.

12. Prager $\mathrm{R}$, Schernthaner $\mathrm{G}$, Graf $\mathrm{H}$ : Effect of metformin on peripheral insulin sensitivity in non-insulin dependent diabetes mellitus. Diabetes Metab 1986, 12:346-350.

13. Evans JM, Donnelly LA, Emslie-Smith AM, Alessi DR, Morris AD: Metformin and reduced risk of cancer in diabetic patients. BMJ 2005, 330:1304-1305.

14. Zakikhani M, Dowling R, Fantus IG, Sonenberg N, Pollak M: Metformin is an AMP kinase-dependent growth inhibitor for breast cancer cells. Cancer Res 2006, 66:10269-10273.

15. Sahra IB: The combination of metformin and 2-deoxyglucose inhibits autophagy and induces AMPK-dependent apoptosis in prostate cancer cells. Autophagy 2010, 6:670-671.

16. Kato K, Gong J, Iwama H, Kitanaka A, Tani J, Miyoshi H, Nomura K, Mimura S, Kobayashi M, Aritomo Y, Kobara H, Mori H, Himoto T, Okano K, Suzuki Y, Murao K, Masaki T: The antidiabetic drug metformin inhibits gastric cancer cell proliferation in vitro and in vivo. Mol Cancer Ther 2012, 11:549-60

17. Jiralerspong S, Palla SL, Giordano SH, Meric-Bernstam F, Liedtke C, Barnett CM, Hsu L, Hung MC, Hortobagyi GN, Gonzalez-Angulo AM: Metformin and pathologic complete responses to neoadjuvant chemotherapy in diabetic patients with breast cancer. J Clin Oncol 2009, 27:3297-3302

18. Hirsch HA, lliopoulos D, Tsichlis PN, Struhl K: Metformin selectively targets cancer stem cells, and acts together with chemotherapy to block tumor growth and prolong remission. Cancer Res 2009, 69:7507-7511.

19. Rattan R, Graham RP, Maguire JL, Giri S, Shridhar V: Metformin suppresses ovarian cancer growth and metastasis with enhancement of cisplatin in vivo. Neoplasia 2011, 13:483-491.

20. Janjetovic K, Vucicevic L, Misirkic M, Vilimanovich U, Tovilovic G, Zogovic N Nikolic Z, Jovanovic S, Bumbasirevic V, Trajkovic V, Harhaji-Trajkovic L: Metformin reduces cisplatin-mediated apoptotic death of cancer cells through AMPK-independent activation of Akt. Eur J Pharmacol 2011, 651:41-50.

21. Palanimuthu D, Shinde SV, Somasundaram K, Samuelson AG: In vitro and in vivo anticancer activity of copper bis(thiosemicarbazone) complexes. $J$ Med Chem 2013, 56:722-734.

22. Donnelly PS, Liddell JR, Lima S, Paterson BM, Cater MA, Savva MS, Mot Al, James JL, Trounce IA, White AR, Crouch PJ: An impaired mitochondrial electron transport chain increases retention of the hypoxia imaging agent diacetylbis(4-methylthiosemicarnazonato)copper". Proc Natl Acad Sci U S A 2012, 109:47-52.

23. French FA, Freedlander BL: Carcinostatic action of polycarbonyl compounds and their derivatives: IV. Glyoxal bis(thiosemicarbazone) and derivatives. Cancer Res 1958, 18:1290-1300.

24. Crowley AR, Dilworth JR, Donnelly PS, Gee AD, Heslop JM: Acetylacetone bis(thiosemicarbazone) complexes of copper and nickel: towards new copper radiopharmaceuticals. Dalton Trans 2004, 2404-2412.

25. Veale RB, Thornley AL: Increased single class low-affinity EGF receptors expressed by human oesophageal squamous carcinoma cell lines. S Afr J Sci 1989, 85:375-379.

26. Bey E, Alexander J, Whitcutt JM, Hunt JA, Gear JH: Carcinoma of the esophagus in Africans: establishment of a continuously growing cell line from a tumor specimen. In Vitro 1976, 12:107-114.

27. Liu B, Fang M, Lu Y, Fan Z: Fibroblast growth factor and insulin-like growth factor differentially modulate the apoptosis and $\mathrm{G} 1$ arrest induced by anti-epidermal growth factor receptor monoclonal antibody. Oncogene 2001, 20:1913-1922.

28. Brouwers EEM, Tibben MM, Pluim D, Rosing H, Boot H, Cats A, Schellens $J H M$, Beijnen, JH: Inductively coupled plasma mass spectrometric analysis of the total amount of platinum in DNA extracts from peripheral blood mononuclear cells and tissue from patients treated with cisplatin. Anal Bioanal Chem 2008, 391:577-585.
29. Smith DJ, Cossins LR, Hatzinisiriou I, Haber M, Nagley P: Lack of correlation between MYCN expression and the Warburg effect in neuroblastoma cell lines. BMC Cancer 2008, 8:259.

30. Damelin LH, Coward S, Choudhury SF, Chalmers S, Cox IJ, Robertson NJ, Revial G, Miles M, Tootle R, Hodgson HJF, Selden C: Altered mitochondrial function and cholesterol synthesis influences protein synthesis in extended HepG2 spheroid cultures. Arch Biochem Biophys 2004, 434:167-77.

31. Kosower NS, Kosower EM, Newton GL, Ranney HM: Bimane fluorescent labels: labelling of normal human red cells under physiological conditions. Proc Natl Acad Sci U S A 1979, 79:3382-3386.

32. Griffith OW: Mechanism of action, metabolism, and toxicity of buthionine sulfoximine and its higher homologs potent inhibitors of glutathione synthesis. J Biol Chem 1982, 257:13704-13712.

33. Shaw RJ, Lamia K, Vasquez D, Koo S-H, Bardeesy N, Depinho R, Montminy M, Cantley LC: The kinase LKB1 mediates glucose homeostasis in liver and therapeutic effects of metformin. Science 2005, 310:1642-6.

34. Lu SC: Regulation of glutathione synthesis. Mol Aspects of Med 2009, 30:42-59.

35. Zafarullaha M, Lia WQ, Sylvestera J, Ahmad M: Molecular mechanisms of $\mathrm{N}$-acetylcysteine actions. Cell Mol Life Sci 2003, 60:6-20.

36. Elstrom RL, Bauer DE, Buzzai M, Karnauskas R, Harris MH, Plas DR, Zhuang $H$, Cinalli RM, Alavi A, Rudin CM, Thompson CB: Akt stimulates aerobic glycolysis in cancer cells. Cancer Res 2004, 64:3892-3899.

37. Jorgenson TC, Zhong W, Oberley TD: Redox imbalance and biochemical changes in cancer. Cancer Res 2013, 73:6118-6123.

38. Cairns R, Harris IS, Mak TW: Regulation of cancer cell metabolism. Nat Rev Cancer 2011, 11:85-95.

39. Vander Heiden MG: Targeting cancer metabolism: a therapeutic window opens. Nat Rev Drug Discovery 2011, 10:671-84.

40. Paz MM: Reductive activation of mitomycin C by thiols: kinetics, mechanism, and biological implications. Chem Res Toxicol 2009, 22:1663-1668.

41. Paterson BM, Donnelly PS: Copper complexes of bis(thiosemicarbazones): from chemotherapeutics to diagnostic and therapeutic radiopharmaceuticals. Chem Soc Rev 2011, 40:3005-18

42. Tardito S, Marchiò L: Copper compounds in anticancer strategies. Curr Med Chem 2009, 16:1325-48.

43. Shankar LK: The clinical evaluation of novel imaging methods for cancer management. Nat Rev Clinical Oncology 2012, 9:738-744.

doi:10.1186/1471-2407-14-314

Cite this article as: Damelin et al:: Metformin induces an intracellular reductive state that protects oesophageal squamous cell carcinoma cells against cisplatin but not copper-bis(thiosemicarbazones). BMC Cancer 2014 14:314.

\section{Submit your next manuscript to BioMed Central and take full advantage of:}

- Convenient online submission

- Thorough peer review

- No space constraints or color figure charges

- Immediate publication on acceptance

- Inclusion in PubMed, CAS, Scopus and Google Scholar

- Research which is freely available for redistribution 